\title{
Enantiomeric Fraction of Selected Chiral Polychlorinated Biphenyls in Cow, Goat, and Ewe Milk and Dairy Products by Heart-Cut Multidimensional Gas Chromatography: First Results
}

\author{
L. R. Bordajandi ${ }^{1,2}$ and M. J. González \\ Department of Instrumental Analysis and Environmental Chemistry, Institute of Organic Chemistry (IQOG), \\ Consejo Superior de Investigaciones Científicas (CSIC), Juan de la Cierva 3, 28006 Madrid, Spain
}

\section{ABSTRACT}

The concentration of the most relevant polychlorinated biphenyl $(\mathrm{PCB})$ congeners has been determined in milk and dairy products (i.e., cheese and yogurt, from cow, goat, and ewe). In addition, the enantiomeric composition of 11 atropisomeric PCB has been determined for the first time in this type of product, using heart-cut multidimensional gas chromatography and 2 enantioselective columns for the unambiguous determination of both enantiomers. Results showed a deviation from the racemic composition for PCB 135, 136, 176, 171 , and 183 in the samples analyzed. Whereas PCB 135, 136, and 176 showed an enrichment of the first eluted enantiomer, congeners 171 and 183 showed an enrichment of the first or second eluted enantiomer depending on the dairy product and species. The remaining congeners analyzed (PCB 84, 91, 95, 132, 149, and 174) did not present a clear enrichment of any of the enantiomers. Therefore, differences in the enantiomeric composition of some of the target atropisomeric PCB have been found among the 3 species and among the milk samples and the related dairy products analyzed. Enantioselective species-dependent processes, as well as enantioselective processes carried on by microorganisms during the fermentation and ripening in the latter could be possible explanations for the differences observed. However, changes in the enantiomeric composition are still not well understood, and further investigation in this direction is recommended.

Key words: milk and dairy product, chiral polychlorinated biphenyl, enantiomeric fraction, multidimensional gas chromatography

\footnotetext{
Received August 5, 2007

Accepted October 19, 2007.

${ }^{1}$ Corresponding author: Luisa.Ramos-Bordajandi@ec.europa.eu

${ }^{2}$ Present address: European Commission, Joint Research Centre (JRC), Institute for Reference Materials and Measurements (IRMM), Retieseweg 111, B-2440 Geel, Belgium.
}

\section{INTRODUCTION}

Polychlorinated biphenyls (PCB) are still contaminants of great environmental concern although their use was banned years ago. Due to their persistence and lipophilic character, they tend to concentrate in the food chain, particularly associated with fat. The ingestion of contaminated food is the main route of nonoccupational human exposure, and as the major source, foodstuff of animal origin (Charnley and Doull, 2005; Darnerud et al., 2006). The studies on the levels of PCB in food commodities are numerous. These studies mainly deal with the determination of a number of congeners, being especially relevant the so-called coplanar or dioxin-like congeners (i.e., non- and mono-ortho PCB) that may exert a similar toxicity to the 2,3,7,8-substituted polychlororinated dibenzo-p-dioxins and furans (Van den Berg et al., 2006), as well as the 7 indicator PCB used for monitoring purposes (Cochran and Frame, 1999). However, the determination of chiral PCB and their enantiomeric enrichment in different matrices has also become a relevant issue in recent years. From the 209 possible PCB congeners, 78 show axial chirality in their nonplanar conformation, and 19 out of those 78 were predicted to exist as stable atropisomers at room temperature due to restricted rotation around the central C-C bond (Kaiser, 1974). Although atropisomeric PCB were released into the environment as racemates, studies showed that many organisms are able to selectively accumulate, degrade, or both, one of the enantiomers (Hühnerfuss et al., 1995; Chu et al., 2003). Additionally, some studies point to different biological and toxic behavior of each of the enantiomers (Rodman et al., 1991). The enantioselective analysis would then provide a more comprehensive understanding of the bioaccumulation, metabolism, and toxicity of those compounds.

For the enantioselective analysis, capillary columns with enantioselective stationary phases based mainly on $\beta$-cyclodextrins ( $\beta$-CD) are used. Chirasil-Dex $(2,3,6$ tri- $O$-methyl $\beta$-CD) is one of the most commonly used enantioselective columns (Schurig and Glausch, 1993; Haglund and Wiberg, 1996; Cochran and Frame, 1999), 
as well as tert-butyldimethylsilyl substituted $\beta$-CD, that have also shown the ability to resolve into enantiomers those PCB presenting a 2,3,4,6-substitution pattern (Vetter et al., 1997a; Bordajandi et al., 2005a). Even so, the choice of a chiral selector is still a matter of trial and error, and up to now, no single enantioselective capillary column has been able to separate simultaneously all 19 chiral PCB into enantiomers. Therefore, complete information about all congeners can be only obtained by the combined used of selected capillary columns. In addition, when analyzing real samples by conventional one-dimensional GC, coelution problems increase due to the duplication of peaks. The use of multidimensional GC techniques then becomes of great value (Vetter and Schurig, 1997b; Cochran and Frame, 1999). Heart-cut multidimensional GC (MDGC) has been the main instrumental technique used (Vetter and Schurig, 1997b), although in the last years, comprehensive 2-dimensional GC $(\mathrm{GC} \times \mathrm{GC})$, with its enhanced separation capacity, has also been applied for the enantioselective analysis of PCB in complex samples (Harju et al., 2003; Bordajandi et al., 2005b).

Studies in the field of PCB enantioselective analysis dealt with the determination of the enantiomeric composition in a wide range of environmental matrices including biota and sediments (Vetter and Schurig, 1997b; Morrissey et al., 2007). Studies in food samples are scarce, although some studies have been carried out in human milk samples (Glausch et al., 1995; Blanch et al., 1999; Bordajandi et al., 2007).

In the present study, the concentration of the most relevant PCB congeners and the enantiomeric composition of 11 chiral PCB were determined in milk and dairy products made of milk of 3 different species: cow, goat, and ewe. Heart-cut multidimensional gas chromatography using 2 different enantioselective columns was used for the unambiguous determination of both enantiomers. The aim of the study was to assess the enantiomeric composition of the chiral PCB in the dairy samples as well as to evaluate the possible differences between species and between the different dairy products. A further purpose was to gain knowledge on the stereochemistry of the chiral PCB that reach the human body through the diet.

\section{MATERIALS AND METHODS}

\section{Standards and Reagents}

All reagents used for the analysis of $\mathrm{PCB}$ were of trace analysis grade. Acetone Pestipur grade were supplied from SDS (Peypin, France). $n$-Hexane, sulfuric acid (95 to $97 \%$ ), and silica gel were supplied from Merck Co. (Darmstadt, Germany) and granular anhydrous sodium sulfate from J.T. Baker (Deventer, the Nether- lands). The PCB standards were purchased from Dr. Ehrenstorfer (Ausburg, Germany).

\section{Milk and Dairy Products Samples}

Whole milk, cheese, and yogurt samples from 3 different species (i.e., cow, goat, and ewe) were analyzed. A total of 3 milk samples and 3 cheese samples from each of the species were included in the study. Cow milk was commercially available, whereas ewe and goat milk samples were obtained from different farms around Madrid. Cheese samples were commercially available. To assure that they were made from pure milk from each species, they were all under the Spanish "denominación de origen" (protected denomination origin) because the protected denomination origin imposes a strict control in the elaboration of the cheeses, including the type of milk used in the elaboration of the product. Two samples of yogurt made of milk from each of the 3 species were also acquired in supermarkets.

\section{Analytical Procedure}

Sample Preparation. Milk and yogurt samples were freeze-dried before analysis, whereas cheese was kept at $4^{\circ} \mathrm{C}$ until analysis. Samples were prepared according to a previously described method (Bordajandi et al., 2004). Briefly, extraction consisted of a matrix solid-phase dispersion of the sample with anhydrous sodium sulfate and silica gel. The mixture acetone: $n$-hexane (1:1, vol/vol) was used as elution solvent. Further clean-up and lipid removal was achieved by using acid and basic impregnated silica gel multilayer columns using $n$-hexane as elution solvent.

Instrumental Analysis: GC-ECD and Heart-Cut MDGC. The list of PCB analyzed included the monoortho substituted $\mathrm{PCB}$, the set of 7 indicators usually used for monitoring purposes as well as those chiral congeners present in commercial PCB mixtures and food samples (PCB 28, 45, 52, 84, 91, 95, 101, 105, 114, $118,123,132,135,136,138,149,153,156,157,167$, $170,171,174,176,180,183,189$, and 194). Analyses were carried out on a Varian 34000 CX GC (Palo Alto, CA) equipped with a BPX-5 column $(60 \mathrm{~m} \times 0.25 \mathrm{~mm}$ I.D., $0.25 \mu \mathrm{m}$ film thickness). Injector and ECD detector temperatures were 280 and $300^{\circ} \mathrm{C}$, respectively. Nitrogen was used as carrier gas. Extracts were injected in splitless mode (splitless time, $1 \mathrm{~min}$ ). The oven temperature program was as follows: $80^{\circ} \mathrm{C}(1 \mathrm{~min})$, at $30^{\circ} \mathrm{C} / \mathrm{min}$ to $185^{\circ} \mathrm{C}(3 \mathrm{~min})$, at $1.9^{\circ} \mathrm{C} / \mathrm{min}$ to $234^{\circ} \mathrm{C}(65.5 \mathrm{~min})$, at $2^{\circ} \mathrm{C} / \mathrm{min}$ to $270^{\circ} \mathrm{C}$. Under this condition PCB 84 coeluted with PCB 101.

The enantiomeric composition of 11 chiral PCB (i.e., PCB 84, 91, 95, 132, 135, 136, 149, 171, 174, 176, and 
183) was determined using a heart-cut MDGC system (Varian Iberica, Madrid, Spain) equipped with 2 independent ovens. Column switching was achieved by means of a Deans valve placed in the first oven. Transfer line was maintained at $280^{\circ} \mathrm{C}$. A nonenantioselective DB5 column $(30 \mathrm{~m} \times 0.25 \mathrm{~mm}$ i.d., $0.25-\mu \mathrm{m}$ film thickness, J\&W Scientific, Folsom, CA) was used as precolumn in the first oven. In the second oven, 2 enantioselective columns were used as main columns: Chirasil-Dex (2,3,6-tri- $O$-methyl $\beta$-CD, $25 \mathrm{~m} \times 0.25 \mathrm{~mm}$ i.d., 0.25 $\mu \mathrm{m}$ film thickness, Varian-Chrompack, Middelburg, the Netherlands) for the analysis of PCB 91, 95, 132, 136, 149,174 , and 176, and a BGB-172 (25\% 2,3,6-tertbutyldimethylsilyl $\beta$-CD, $30 \mathrm{~m} \times 0.25 \mathrm{~mm}$ i.d., $0.18 \mu \mathrm{m}$ film thickness, BGB Analytik, Adliswil, Switzerland) for the analysis of PCB 84, 135, 171, and 183. Injections were performed at $270^{\circ} \mathrm{C}$ in the splitless mode (splitless time, $1 \mathrm{~min})$. Both ovens were equipped with a ${ }^{63} \mathrm{Ni}$ $\mathrm{ECD}$, maintained at 300 and $250^{\circ} \mathrm{C}$ for the monitor and main detector, respectively. Nitrogen was used as carrier gas. Details of the chromatographic conditions are described elsewhere (Bordajandi et al., 2005a).

Lipid Determination. The lipid content was determined by matrix solid-phase dispersion using a mixture chloroform:methanol $(1: 1, \mathrm{vol} / \mathrm{vol})$ as elution solvent. The extract was evaporated until dryness, and the lipid content was determined gravimetrically.

Quality Control and Assurance. To ensure the quality of the analysis, blank samples covering the whole analytical procedure were performed to check the absence of background contamination. Our laboratory has participated in different international interlaboratory studies and several international quality control studies for the analysis of PCB and 2,3,7,8-substituted polychlororinated dibenzo- $p$-dioxins and furans in different food matrices, including milk and human milk samples (National Institute of Public Health, Norway, 2001, 2005). The results were consistent at all times with the consensus means given by the interlaboratory organization.

\section{RESULTS AND DISCUSSION}

\section{Total PCB Concentrations and Accumulation Profile}

In Table 1 the total PCB concentration in the samples analyzed are shown, expressed in nanograms per gram on a lipid weight basis (l.w.). Total PCB concentration in milk samples ranged from 3.55 to $39.3 \mathrm{ng} / \mathrm{g}$ l.w., presenting cow milk higher concentrations (5.94 to 39.9 ng/g l.w.) than ewe (3.55 to $11.5 \mathrm{ng} / \mathrm{g}$ l.w.) and goat milk samples (4.93 to $9 \mathrm{ng} / \mathrm{g}$ l.w.). Concentrations found for cheese samples ranged from 11.0 to $19.9 \mathrm{ng} / \mathrm{g}$ l.w., except for the goat cheese 1 that showed a value of $30 \mathrm{ng} /$ g l.w. Concerning the yogurt samples analyzed, one of
Table 1. Concentration of total polychlorinated biphenyls (PCB) and coplanar PCB, expressed in nanograms per gram on a lipid basis in the milks and dairy products analyzed

\begin{tabular}{lcc}
\hline & \multicolumn{2}{c}{ Concentration (ng/g of lipid weight) } \\
\cline { 2 - 3 } Sample & Total PCB & $\begin{array}{c}\text { Coplanar PCB } \\
\text { Mono-ortho PCB }\end{array}$ \\
\hline Cow milk 1 & 39.3 & 1.63 \\
Cow milk 2 & 5.94 & 0.323 \\
Cow milk 3 & 17.1 & 1.51 \\
Goat milk 1 & 4.93 & 0.591 \\
Goat milk 2 & 6.89 & 0.553 \\
Goat milk 3 & 9.00 & 1.04 \\
Ewe milk 1 & 3.55 & 0.225 \\
Ewe milk 2 & 11.5 & 0.556 \\
Ewe milk 3 & 10.6 & 0.518 \\
Cow cheese 1 & 12.2 & 2.21 \\
Cow cheese 2 & 16.6 & 1.12 \\
Cow cheese 3 & 12.9 & 1.05 \\
Goat cheese 1 & 30.0 & 2.56 \\
Goat cheese 2 & 11.0 & 0.664 \\
Goat cheese 3 & 12.7 & 0.842 \\
Ewe cheese 1 & 12.5 & 0.744 \\
Ewe cheese 2 & 19.9 & 1.69 \\
Ewe cheese 3 & 12.6 & 0.888 \\
Cow yogurt 1 & 6.60 & 0.640 \\
Cow yogurt 2 & 26.7 & 7.67 \\
Goat yogurt 1 & 10.7 & 0.445 \\
Goat yogurt 2 & 7.26 & 0.316 \\
Ewe yogurt 1 & 6.96 & 0.475 \\
Ewe yogurt 2 & 11.3 & 0.782 \\
\hline & &
\end{tabular}

the cow yogurt samples showed a value of $26.7 \mathrm{ng} / \mathrm{g}$ l.w., whereas for the rest concentrations ranged from 6.6 to $11.3 \mathrm{ng} / \mathrm{g}$ l.w. Storelli et al. (2001) reported PCB concentrations for cow, goat, and sheep milk from Italy. The levels found for cow milk ( 34.5 to $66.7 \mathrm{ng} / \mathrm{g}$ l.w.) were higher than those reported in the present study, as well as PCB concentrations in goat and ewe milk (20.2 ng/g l.w.). Values of $4.7 \mathrm{ng} / \mathrm{g}$ for the sum of the indicator PCB were found in cheese samples from the Netherlands (Baars et al., 2004), whereas Santos et al. (2006) reported concentrations of $33.82 \pm 18.28 \mathrm{ng} / \mathrm{g}$ l.w. in samples from Brazil. The most abundant congeners in the dairy samples in the present study were those with a lower chlorination degree such as PCB 28, 52 , and 95 followed by congeners 153, 138, and 180 . The accumulation profile in the dairy products resembled that of the milk samples. In addition, no remarkable differences were found between the 3 species. In Figure 1 the mean accumulation profile in milk of the 3 species is shown, as well as the mean accumulation profile in the goat milk and its dairy products. These accumulation profiles differ from that found in breast milk samples, where PCB 153, 138, and 180 clearly dominated the accumulation pattern (Bordajandi et al., 2007). This points to a different metabolism ability, accumulation profile, or both, for the low chlorinated PCB in humans and in the 3 different species under study. The contribution of the mono-ortho substituted 
a)

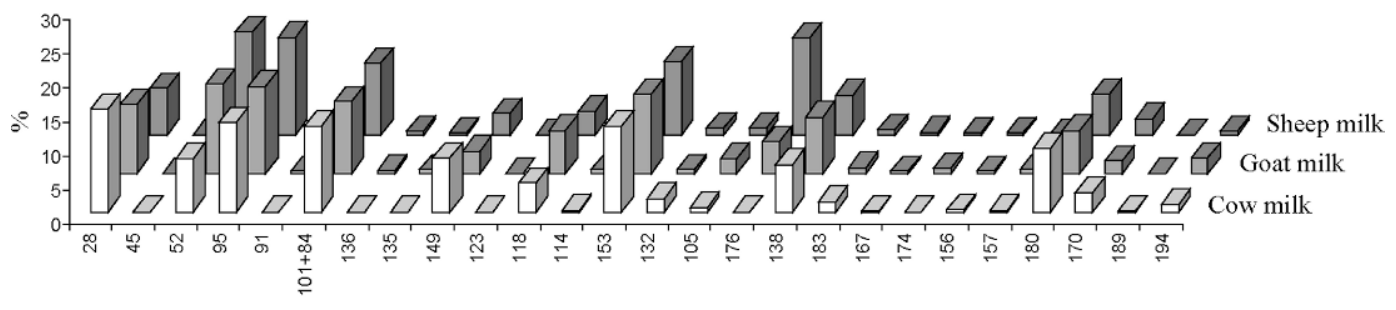

b)

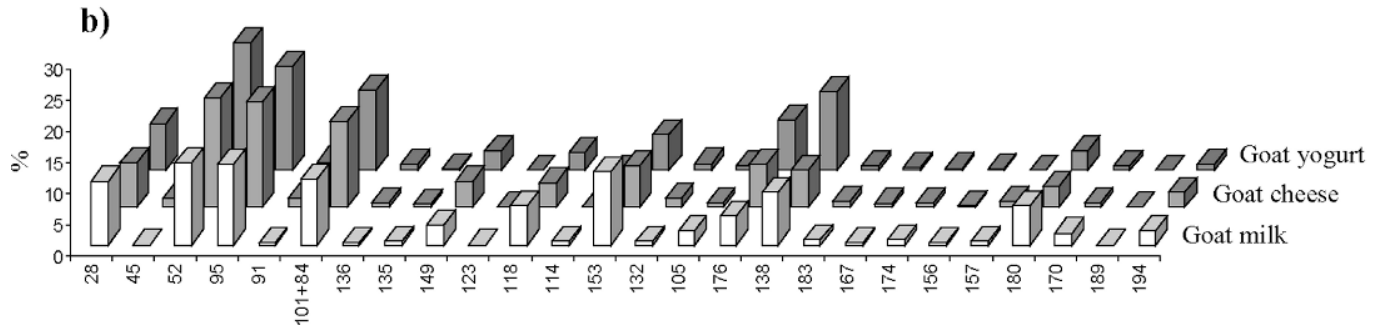

Figure 1. Mean polychlorinated biphenyl accumulation profile in the a) milk samples analyzed from the 3 different species and b) in the goat milk, cheese, and yogurt samples.

congeners analyzed to the total PCB content ranged from 4 to $12 \%$, although in one of the cow cheese and yogurt samples, cow cheese 1 and cow yogurt 2, they accounted for 18 and 29\%, respectively. From the 8 mono-ortho PCB analyzed, the most abundant one was PCB 118, followed by PCB 105.

\section{Enantiomeric Composition}

To describe the enantiomeric composition, the enantiomeric ratio (ER), calculated as the ratio of the area of the first eluted enantiomer (E1) divided by the area of the second eluted enantiomer (E2), has been commonly used (Vetter and Schurig, 1997b). However, when using this approach, the ER values range from 0 to undefined, with $\mathrm{ER}=1$ when the mixture is racemic, and consequently, the excesses of the first enantiomer are not equivalent to the excess of the second one. In recent years, the use of the enantiomeric fraction $(\mathbf{E F})$, defined as $\mathrm{EF}=\mathrm{E} 1 /(\mathrm{E} 1+\mathrm{E} 2)$, has gained relevance. In this case, the $\mathrm{EF}$ values range from 0 to 1 , with $\mathrm{EF}=0.5$ for the racemic mixture, the excesses of both enantiomers being equivalent (de Geus et al., 2000). For this reason the latter approach has been preferred in this study. In Table 2 the EF obtained for the milk, cheese, and yogurt samples made of cow, ewe, or goat milk are shown. The enantiomeric composition of PCB 176 was not determined in the cow milk samples, as well as that of PCB 135 and 136 due to interferences in the chromatogram. For the same reason the EF of PCB 171 could not be determined in 2 of the ewe milk samples. Six out of the 11 chiral PCB investigated (PCB 84,
$91,95,132,149$, and 174) showed a racemic or nearly racemic composition in the milk, cheese, and yogurt samples analyzed from the 3 species (Table 2). The PCB 135,136 , and 176 presented in all samples an $\mathrm{EF}<0.5$ (i.e., an enantioenrichment of the second eluted enantiomer). For PCB 135, EF values ranged from 0.33 to 0.50 , showing the goat milk samples the strongest deviation from the racemic $(\mathrm{EF}=0.33-0.44)$. For PCB 136, the values range from 0.37 to 0.49 , whereas for PCB 176 the deviation from the racemic was not so marked (EF $=$ 0.40-0.49). On what concerns PCB 171 and 183, deviations from the racemic were observed in some of the samples analyzed. In cow milk PCB 171 was found to have a nearly racemic composition, whereas ewe milk showed an enrichment of the first eluted enantiomer $(\mathrm{EF}=0.68)$, and for the goat milk samples, opposite results were obtained because one of the samples showed an enrichment of the second enantiomer $(\mathrm{EF}=$ 0.14 ), whereas the other showed an enrichment of the first eluted enantiomer ( $\mathrm{EF}=0.77)$. Regarding the cheese samples, those made of cow milk did not show a clear deviation from the racemic $(\mathrm{EF}=0.46-0.53)$, in line with the results obtained for the cow milk samples. Ewe cheese samples showed an enrichment of the second eluted enantiomer $(\mathrm{EF}=0.37-0.45)$, opposite to that observed for the milk. The goat cheese samples presented a racemic composition with a slight enantioenrichment of the first eluted enantiomer $(\mathrm{EF}=$ 0.52-0.56). Yogurt samples made of cow milk showed a racemic composition, whereas those made of goat and ewe milk showed an enrichment of the second eluted 
Table 2. Enantiomeric fraction of the milk and dairy products analyzed ${ }^{1}$

\begin{tabular}{|c|c|c|c|c|c|c|c|c|}
\hline \multirow[b]{2}{*}{ Item } & \multicolumn{3}{|c|}{ Milk } & \multicolumn{3}{|c|}{ Cheese } & \multicolumn{2}{|c|}{ Yogurt } \\
\hline & 1 & 2 & 3 & 1 & 2 & 3 & 1 & 2 \\
\hline \multicolumn{9}{|l|}{ Cow } \\
\hline PCB 84 & NA & 0.52 & 0.50 & 0.51 & 0.50 & 0.50 & 0.51 & 0.52 \\
\hline РCB 91 & ND & 0.53 & 0.51 & 0.50 & 0.50 & 0.51 & 0.52 & 0.49 \\
\hline PCB 95 & 0.45 & 0.49 & 0.49 & 0.48 & 0.48 & 0.48 & 0.49 & 0.49 \\
\hline PCB 132 & 0.50 & 0.50 & 0.50 & 0.49 & 0.49 & 0.50 & 0.50 & 0.50 \\
\hline PCB 135 & 0.50 & int & int & 0.43 & 0.43 & 0.47 & 0.49 & 0.49 \\
\hline PCB 136 & int & 0.47 & 0.49 & 0.46 & ND & 0.47 & 0.49 & 0.47 \\
\hline PCB 149 & int & 0.51 & 0.51 & 0.49 & 0.49 & 0.50 & 0.49 & 0.49 \\
\hline PCB 171 & 0.55 & 0.45 & 0.46 & 0.53 & 0.50 & 0.46 & 0.50 & 0.46 \\
\hline PCB 174 & 0.51 & 0.51 & 0.50 & 0.48 & 0.48 & 0.47 & 0.50 & 0.48 \\
\hline PCB 176 & NA & NA & NA & 0.40 & 0.43 & 0.42 & 0.48 & 0.49 \\
\hline PCB 183 & 0.48 & 0.48 & 0.48 & 0.50 & 0.51 & 0.53 & 0.49 & 0.49 \\
\hline \multicolumn{9}{|l|}{ Goat } \\
\hline PCB 84 & NA & 0.52 & 0.53 & 0.49 & 0.48 & 0.51 & 0.50 & 0.53 \\
\hline РCB 91 & 0.52 & 0.50 & 0.51 & 0.50 & 0.50 & 0.49 & ND & 0.48 \\
\hline PCB 95 & 0.50 & 0.49 & 0.49 & 0.48 & 0.51 & 0.50 & 0.49 & 0.49 \\
\hline PCB 132 & 0.49 & 0.50 & 0.50 & 0.49 & 0.51 & 0.49 & 0.49 & 0.49 \\
\hline PCB 135 & 0.44 & 0.33 & 0.34 & 0.48 & 0.43 & 0.42 & 0.46 & 0.41 \\
\hline PCB 136 & 0.48 & 0.40 & 0.48 & 0.44 & 0.45 & ND & 0.38 & 0.41 \\
\hline PCB 149 & 0.48 & 0.49 & 0.49 & 0.50 & 0.51 & 0.50 & 0.47 & 0.49 \\
\hline PCB 171 & 0.14 & ND & 0.77 & ND & 0.56 & 0.52 & 0.39 & 0.42 \\
\hline PCB 174 & 0.48 & 0.48 & 0.47 & 0.49 & 0.49 & 0.48 & 0.46 & 0.47 \\
\hline PCB 176 & 0.40 & 0.42 & 0.41 & ND & 0.41 & 0.40 & 0.43 & 0.43 \\
\hline PCB 183 & 0.25 & 0.40 & 0.39 & 0.48 & 0.50 & 0.48 & 0.44 & 0.46 \\
\hline \multicolumn{9}{|l|}{ Ewe } \\
\hline PCB 84 & 0.53 & 0.51 & 0.57 & 0.51 & 0.49 & 0.52 & 0.50 & 0.50 \\
\hline PCB 91 & 0.52 & 0.52 & 0.56 & 0.53 & 0.50 & 0.50 & 0.49 & int \\
\hline РCB 95 & 0.51 & 0.49 & 0.49 & 0.49 & 0.49 & 0.48 & 0.50 & 0.49 \\
\hline PCB 132 & 0.50 & 0.49 & 0.49 & 0.49 & 0.49 & 0.49 & 0.49 & 0.49 \\
\hline PCB 135 & 0.43 & 0.44 & 0.46 & 0.44 & 0.41 & 0.44 & 0.43 & 0.44 \\
\hline PCB 136 & 0.49 & 0.48 & 0.48 & 0.37 & 0.44 & 0.41 & ND & 0.46 \\
\hline PCB 149 & 0.49 & 0.49 & 0.50 & 0.50 & 0.50 & 0.49 & 0.49 & 0.50 \\
\hline PCB 171 & int & int & 0.68 & 0.45 & 0.43 & 0.37 & 0.36 & 0.38 \\
\hline PCB 174 & 0.47 & 0.48 & 0.50 & 0.48 & 0.49 & 0.49 & 0.48 & 0.49 \\
\hline PCB 176 & 0.40 & 0.43 & 0.44 & 0.43 & 0.42 & 0.44 & 0.49 & 0.44 \\
\hline PCB 183 & 0.31 & 0.31 & 0.40 & 0.45 & 0.44 & 0.41 & 0.41 & 0.41 \\
\hline
\end{tabular}

${ }^{1} \mathrm{PCB}=$ polychlorinated biphenyls; $\mathrm{NA}=$ not analyzed; $\mathrm{ND}=$ not detected; int $=$ not determined due to interference problems.

enantiomer $(\mathrm{EF}=0.39-0.42$ and $\mathrm{EF}=0.36-0.38$, respectively).

If the results for the milk and dairy products from one of the species (e.g., cow) are studied, milk and dairy products showed no clear enantioenrichment of PCB 171. Ewe's milk showed an enrichment of the first eluted enantiomer, whereas cheese samples and yogurt from the same species present an enrichment of the second eluted enantiomer. In the case of the goat samples, differing results were found: whereas no enantioenrichment was found in the cheese samples, yogurts presented and enrichment of the second eluted enantiomer and the 2 milk samples showed opposite results.

Regarding PCB 183, whereas cow milk samples showed a racemic composition $(\mathrm{EF}=0.48)$, goat and ewe milk samples showed an enantioenrichment of the second eluted enantiomer $(\mathrm{EF}=0.25-0.40$ and $0.31-0.40$, respectively). Cow cheese samples showed no enrichment of any of the enantiomers $(\mathrm{EF}=0.50-0.53)$, similar to the results obtained for the cow milk. Goat cheese samples also showed a racemic composition. This nearly racemic composition can be outlined against the enrichment of the second eluting enantiomer in the corresponding milk samples. The enantiomeric composition in the ewe cheese samples showed an enrichment of the second eluted enantiomer $(\mathrm{EF}=$ 0.41-0.45), as well as in the milk samples. Yogurt samples made of cow milk showed no enantioenrichment, whereas those made of goat and ewe milk showed an enrichment of the second enantiomer $(\mathrm{EF}=0.44-0.46$ and $\mathrm{EF}=0.41$, respectively). Again, cow milk products showed no clear enantioenrichment, whereas in products made of goat or ewe milk, an enrichment of the second eluted enantiomer is observed. In Figure 2 the chromatogram obtained for the enantiomers of PCB 183 in milk, cheese, and yogurt samples made of goat milk is shown. 


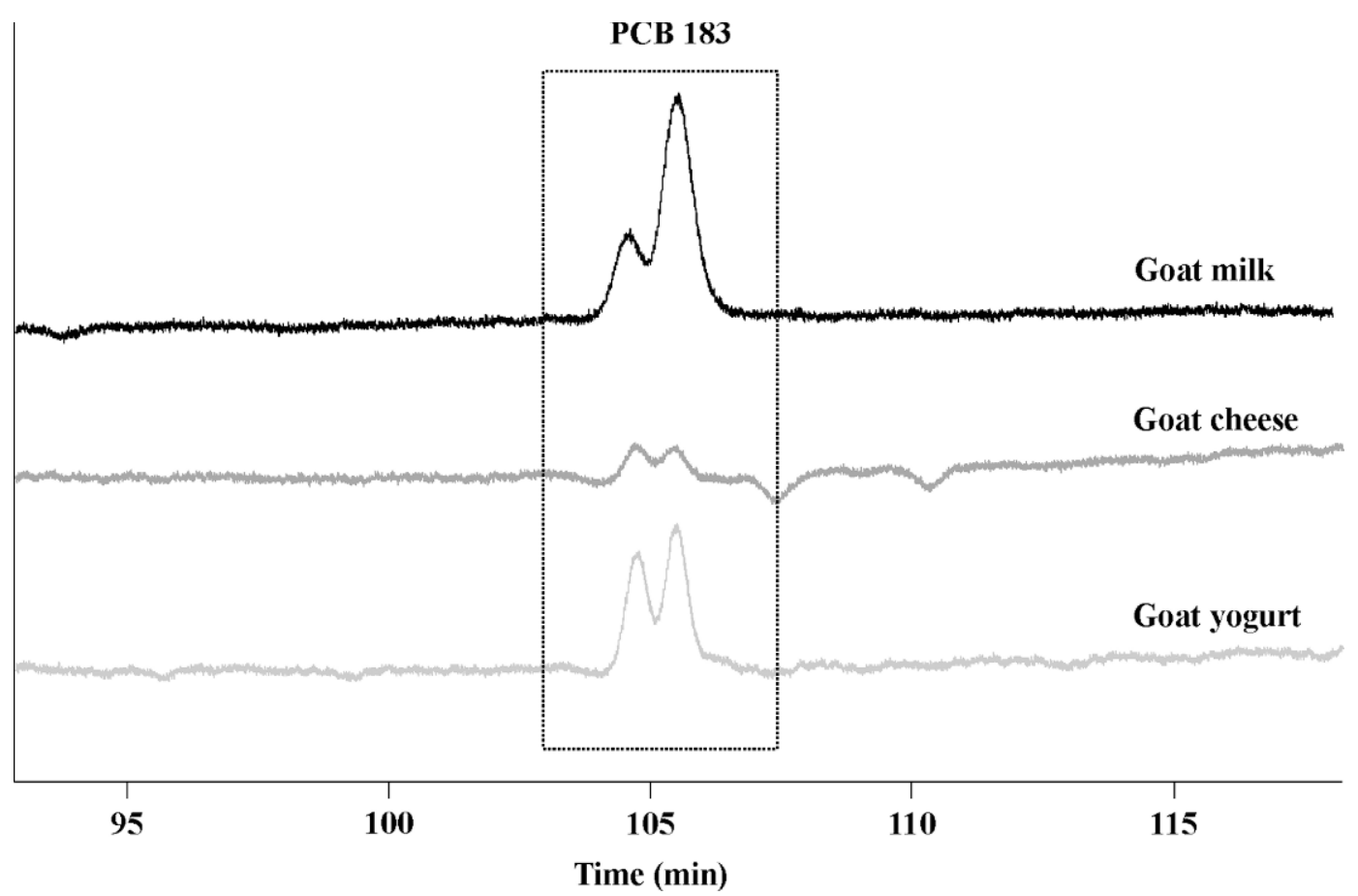

Figure 2. Chromatogram obtained for polychlorinated biphenyl (PCB) 183 in one of the milk, cheese, and yogurt samples made of goat milk using the enantioselective column BGB-172.

To summarize, PCB 135, 136, 176, 171, and 183 showed deviation from the racemic composition in the samples analyzed. For PCB 135, 136, and 176, an enrichment of the first eluted enantiomer was observed, whereas for congeners 171 and 183 the enrichment was for the first or second eluted enantiomer, depending on the dairy products and species. The remaining congeners analyzed (PCB 84, 91, 95, 132, 149, and 174) did not present a clear enrichment of any of the enantiomers.

As far as the authors know, there are no previous studies of the enantiomeric composition in milk, dairy products, or both. Thus, these first results obtained in the present study can only be compared with those recently published about the enantiomeric composition in human breast milk samples (Glausch et al., 1995; Blanch et al., 1999; Bordajandi et al., 2007). For PCB 132 , breast milk samples showed an enrichment of the second eluted enantiomer, whereas a racemic composition was found in the milk samples from cow, ewe, and goat. The PCB 91, 95, and 149 showed a racemic composition and congener 176 an enrichment of the first eluted enantiomer, both in the breast milk samples and the milk from the 3 species studied. For PCB 84 and 174 , cow, ewe, and goat samples showed no enantioenrichment, whereas for the breast milk samples a nonracemic composition was found. On the other hand, PCB 135 showed a racemic composition in the breast milk samples, whereas a nonracemic composition was found in the present study. It is important to mention that in both studies the same enantioselective columns were used.

Among the processes that could be involved in the selective depletion of one of the enantiomers, enantioselective enzymatic degradation due to the differences in species should be considered, together with the microbiological degradation. Although PCB are very stable compounds, they can undergo microbiological degradation, mainly through aerobic oxidation and microbial reductive dehalogenation (Furukawa, 2000; Wiegel and $\mathrm{Wu}, 2000$ ). Although it cannot be ruled out the fact that PCB could be already present in a nonracemic composition in the feedstuff those animals eat, the differences observed between milk samples and the related dairy products made of ewe and goat milk could be explained by enantioselective processes carried on by microorganisms during the fermentation and ripening in the latter.

\section{CONCLUSIONS}

The most remarkable findings of this study were the differences found in the enantiomeric composition of some of the atropisomeric target PCB among the species and the different dairy products analyzed. Deviations from the racemic were specially found for PCB 135, 
$136,171,176$, and 183. A number of reasons could explain the enantioselective accumulation/degradation of one of the enantiomers against the other, such as enantioselective enzymatic transformation that might be species-dependent, and microbiological degradation or nonracemic PCB uptake, or both, from feedstuff. However, changes in the enantiomeric composition are still not well understood, and further investigation in this direction is recommended. Because the 2 enantiomers might exhibit a different biological response, such as toxicity, information about the enantiomeric composition of chiral organochlorine compounds in food becomes a matter of concern because ingestion of food is the main way of human exposure.

\section{ACKNOWLEDGMENTS}

The authors thank Comunidad Autónoma de Madrid (CAM) for project 07G/0057/2000.

\section{REFERENCES}

Baars, A. J., M. I. Bakker, R. S. Baumann, P. E. Boon, J. I. Freijer, L. A. P. Hoogenboom, R. Hoogerbrugge, J. D. van Klaveren, A. K. D. Liem, W. A. Traag, and J. de Vries. 2004. Dioxins, dioxinlike PCBs and non-dioxin-like PCBs in foodstuffs: Occurrence and dietary intake in the Netherlands. Toxicol. Lett. 151:51-61.

Blanch, G. P., A. Glausch, and V. Schurig. 1999. Determination of the enantiomeric ratios of chiral PCB 95 and 149 in human milk samples by multidimensional gas chromatography with ECD and MS(SIM) detection. Eur. Food Res. Technol. 209:294-296.

Bordajandi, L. R., E. Abad, and M. J. González. 2007. Occurrence of PCBs, PCDD/Fs, PBDEs and DDTs in Spanish breast milk. Enantiomeric fraction of chiral PCBs. Chemosphere doi:10.1016/ j.chemosphere.2007.07.019

Bordajandi, L. R., G. Gómez, E. Abad, J. Rivera, M. M. FernándezBastón, J. Blasco, and M. J. González. 2004. Survey of persistent organic pollutants $(\mathrm{PCBs}, \mathrm{PCDD} / \mathrm{Fs}, \mathrm{PAHs})$, heavy metals $(\mathrm{Cu}$, $\mathrm{Cd}, \mathrm{Zn}, \mathrm{Pb}, \mathrm{Hg}$ ) and arsenic in food samples from Huelva (Spain): Levels, congener distribution and health implications. J. Agric. Food Chem. 52:992-1001.

Bordajandi, L. R., P. Korytár, J. de Boer, and M. J. González. 2005a. Enantiomeric separation of chiral polychlorinated biphenyls on $\beta$-cyclodextrin capillary columns by means of heart-cut multidimensional gas chromatography and comprehensive two dimensional gas chromatography. Application to food samples. J. Sep. Sci. 28:163-171.

Bordajandi, L. R., L. Ramos, and M. J. González. 2005b. Chiral comprehensive two-dimensional gas chromatography with electroncapture detection applied to the analysis of chiral polychlorinated biphenyls in food samples. J. Chromatogr. A. 1078:128-135.

Charnley, G., and J. Doull. 2005. Human exposure to dioxins from food, 1999-2002. Food Chem. Toxicol. 43:671-679.

Chu, S., A. Covaci, and P. Schepens. 2003. Levels and chiral signatures of persistent organochlorine pollutants in human tissues from Belgium. Environ. Res. 93:167-176.

Cochran, J. W., and G. M. Frame. 1999. Recent developments in highresolution gas chromatography of polychlorinated biphenyls. J. Chromatogr. A. 843:323-368.
Darnerud, P. O., S. Atuma, M. Aune, R. Bjerselius, A. Glynn, K. Petersson Grawe, and W. Becker. 2006. Dietary intake estimations of organohalogen contaminants (dioxins, PCB, PBDE and chlorinated pesticides, e.g. DDT) based on Swedish market basket data. Food Chem. Toxicol. 44:1597-1606.

de Geus, H.-J., P. G. Wester, J. de Boer, and U. A. Th. Brinkman. 2000. Enantiomer fractions instead of enantiomer ratios. Chemosphere 41:725-727.

Furukawa, K. 2000. Biochemical and genetic bases of microbial degradation of polychlorinated biphenyls (PCBs). J. Gen. Appl. Microbiol. 46:283-296.

Glausch, A., J. Hahn, and V. Schurig. 1995. Enantioselective determination of chiral $2,2^{\prime}, 3,3^{\prime}, 4,6^{\prime}$-hexachlorobiphenyl (PCB 132) in human milk samples by multidimensional gas chromatography/electron capture detection and by mass spectrometry. Chemosphere 30:2079-2085.

Haglund, P., and K. Wiberg. 1996. Determination of the gas chromatographic elution sequences of the (+) and (-)-enantiomers of stable atropisomeric PCBs on Chirasil-Dex. J. High Res. Chromatogr. 19:373-376.

Harju, M., A. Bergman, M. Olsson, A. Roos, and P. Haglund. 2003. Determination of atropisomeric and planar polychlorinated biphenyls, their enantiomeric fractions and tissue distribution in grey seals using comprehensive $2 \mathrm{D}$ gas chromatography. J. Chromatogr. A. 1019:127-142.

Hühnerfuss, H., B. Pfaffenberger, D. Gehrcke, L. Karbe, W. A. König, and O. Landgraff. 1995. Stereochemical effects of PCBs in the marine environment: Seasonal variation of coplanar and atropisomeric PCBs in blue mussels (Mytilus edulis L.) of the German bight. Mar. Pollut. Bull. 30:332-340.

Kaiser, K. L. E. 1974. On the optical activity of polychlorinated biphenyls. Environ. Pollut. 7:93-101.

Morrissey, J. A., D. S. Bleackley, N. A. Warner, and C. S. Wong. 2007. Enantiomer fraction sof polychlorinated biphenyls in three selected Standard Reference Materials. Chemosphere 66:326331.

Rodman, L. E., S. I. Shedlofsky, A. Mannschreck, M. Püttmann, A. T. Swim, and L. Robertson. 1991. Differential potency of atropisomers of polychlorinated biphenyls on cytochrome P450 induction and uroporphyrin accumulation in the chick embryo hepatocyte culture. Biochem. Pharmacol. 41:915-922.

Santos, J. S., A. A. O. Xavier, E. F. Ries, I. Costabeber, and T. Emanuelli. 2006. Assessment of polychlorinated biphenyls (PCBs) in cheese from Rio Grande do Sul, Brazil. Chemosphere 65:15441550 .

Schurig, V., and A. Glausch. 1993. Enantiomer separation of atropisomeric polychlorinated biphenyls (PCBs) by gas chromatography on Chirasil-Dex. Naturwissenschaften 80:468-469.

Storelli, M. M., A. Storelli, and G. O. Marcotrigiano. 2001. Polychlorinated biphenyls, hexachlorobenzene and organochlorine pesticide residues in milk from Apulia. Ital. J. Food Sci. 13:113-177.

Van den Berg, M., L. S. Birnbaum, M. Denison, M. De Vito, W. Farland, M. Feeley, H. Fiedler, H. Hakansson, A. Hanberg, L. Haws, M. Rose, S. Safe, D. Schrenk, C. Tohyama, A. Tritscher, J. Tuomisto, M. Tysklind, N. Walker, and R. E. Peterson. 2006. The 2005 World Health Organization reevaluation of human and mammalian toxic equivalency factors for dioxins and dioxin-like compounds. Toxicol. Sci. 93:223-241.

Vetter, W., U. Klobes, B. Luckas, and G. Hottinger. 1997a. Enantiomer separation of selected atropisomeric polychlorinated biphenyls including PCB 144 on tert-butyldimethylsilylated $\beta$-cyclodextrin. J. Chromatogr. A. 769:247-252.

Vetter, W., and V. Schurig. 1997b. Enantionselective determination of chiral organochlorine compounds in biota by GC on modified cyclodextrins. J. Chromatogr. A. 774:143-175.

Wiegel, J., and Q. Wu. 2000. Microbial reductive dehalogenation of polychlorinated biphenyls. FEMS Microbiol. Ecol. 32:1-15. 